\title{
The Unusual Track and Rapid Intensification of Cyclone Nargis in 2008 under a Characteristic Environmental Flow over the Bay of Bengal
}

\author{
Hiroyuki YAMADA, Qoosaku MOTEKI, Masanori YOSHIZAKI \\ Japan Agency for Marine-Earth Science and Technology, Yokosuka, Japan
}

(Manuscript received 28 April 2009, in final form 21 October 2009)

\begin{abstract}
Cyclone Nargis in 2008 was the worst natural disaster in the recorded history of Myanmar. Using observational and reanalysis datasets, this paper describes the features of Nargis's track, intensity change, and environmental conditions. The cyclone track, recurving eastward over the Bay of Bengal and reaching Myanmar, is quite rare in the track record of recent 30 years. On the other hand, this record also shows that a limited number of cyclones with similar tracks formed in a concentrated period (i.e., April). Moreover, they are similar to Nargis in terms of undergoing rapid intensification before landfall. An analysis of microwave satellite data revealed a significant change in the structure of Nargis before and after the recurvature. In the analysis of environment, the relevance of a midtropospheric flow to the cyclone's recurvature and structural change is focused. The flow in the north of the bay was characterized by a subtropical jet with low relative humidity in the middle troposphere due to subsidence along the southern slope of the Tibetan Plateau. A southward branch of the dry flow forced the cyclone's movement to change from northward to eastward, while the intrusion of dry air into the cyclone center interrupted the convective development. After the recurvature, this dry flow meandered to the south of the cyclone, and this caused a decrease in vertical shear near the cyclone center, leading to the redevelopment of convection and intensification of the cyclone. The characteristic meander of a midtropospheric dry flow was also analyzed in the environment of the former cyclones that reached Myanmar, suggesting the applicability of a similar scenario to their intensification. These results suggest the importance of a midtropospheric flow as a determinant of cyclone track and intensification over the Bay of Bengal in spring.
\end{abstract}

\section{Introduction}

Nargis (2008) was a devastating tropical cyclone that developed over the Bay of Bengal (hereafter, $\mathrm{BoB})$ in late April and caused catastrophic destruction in the Irrawaddy delta region of Myanmar during its landfall. The maximum wind speed at the surface, estimated by the Joint Typhoon Warning Center (JTWC), reached $63 \mathrm{~ms}^{-1}$ before landfall, which corresponds to a Category-4 storm on the Saffir-Simpson scale or a typhoon on the intensity scale of the Japan Meteorological Agency

Corresponding author: Hiroyuki Yamada, Japan Agency for Marin-Earth Science and Technology, 215 Natsushima-cho, Yokosuka 237-0061, Japan.

E-mail: yamada@jamstec.go.jp

(C) 2010, Meteorological Society of Japan
(JMA). Webster (2008) reported that over 130,000 lives were lost, mainly due to a storm surge of sea water with a depth up to $4 \mathrm{~m}$ that inundated the densely populated low-lying coastal region. This cyclone ranks as the deadliest disaster in the recorded history of the country.

Over the BoB, tropical cyclones with maximum surface winds of $34 \mathrm{knot}\left(17.2 \mathrm{~ms}^{-1}\right)$ and over are characterized by their devastating impact (Alam et al. 2003) although their annual number is only $10 \%$ of the global total (Gray 1968). The loss of lives and property due to storm surge is associated with the geography, such as the low flat coastal terrain and the funnel shape of the bay. A better understanding of cyclone activity in this region, which will lead to better prediction of cyclone track and intensity, is necessary to take precautions 
against the storm surge. As for Cyclone Nargis, it is noteworthy that this cyclone moved eastward over the bay (Webster 2008) while its intensity increased from category 1 to 4 within $24 \mathrm{~h}$ before landfall (Lin et al. 2009). This track is unusual among cyclones in this region because they usually move northward or northwestward and across the northern coast of Bangladesh and India (Singh et al. 2000). The questions for meteorologists about this case are why Nargis followed this unusual course, why it intensified rapidly, and how can the track and intensity be predicted. In this study, we concentrate on the course and intensification of Nargis.

Tropical cyclones tend to form over the BoB in premonsoon (April and May) and postmonsoon (October and November) periods (Singh et al. 2000). Although the frequency of disturbances is high in summer (July-August), more than $80 \%$ of these disturbances are tropical depressions with the maximum surface winds not reaching $17.2 \mathrm{~ms}^{-1}$ (Subbaramayya and Rao 1984). As for Myanmar, Alam et al. (2003) showed that the most vulnerable month for tropical cyclones is May. Thus, Nargis can be classified as a severe spring cyclone. Jain et al. (2006) conducted numerical simulations of storm surges along the Myanmar coast due to cyclone landfall in April and May. The spring season precedes the first transition of the Asian summer monsoon, occurring usually in late May (Hsu et al. 1999), and is characterized by the high sea surface temperature (SST), due to strong solar heating (Sengupta et al. 2002). Tropical cyclones are usually generated in this season under the influence of wave activity over the equator (Frank and Roundy 2006). The background flow in this season is marked by a subtropical jet that meanders along the southern rim of the Tibetan Plateau (Sato and Kimura 2007). However, there is no established theory to explain the effect of these environmental conditions on the track and intensification of the severe spring cyclones. While modeling studies of cyclone evolution in this region have been conducted, most of them have focused on cases in summer (Vaidya et al. 2004) and autumn (Mohanty et al. 2004; Rao and Ashok 1999). Although Pattanayak and Mohanty (2008) recently reported the results of numerical simulations of Cyclone Mala in 2006, which made landfall in Myanmar in April, their concern was to demonstrate the model performance.

As for Nargis, Kikuchi et al. (2009) described the process of the intensification in its early stage and pointed out the role of the Madden-Julian Oscillation (MJO) on cyclone initiation. Kikuchi and Wang (2009) discussed the role of tropical intraseasonal oscillation on the formation of Nargis from a climatological point of view. Lin et al. (2009) highlighted the role of SST, which was significantly higher than the climatological value, on the rapid intensification just before landfall. In the present study, we focus on the relevance of the environmental flow to the track and intensification of Nargis. The data used here are explained in Section 2, and Nargis's track and intensification are described in Section 3, while the change in the cyclone structure and environmental features are described in Sections 4 and 5, respectively. Similarities between these environmental conditions and those of former severe cyclones hitting Myanmar are described in Section 6, and the summary and discussion are presented in Section 7.

\section{Data}

The track data of Nargis and other cyclones since 1979 over the Indian Ocean were obtained from the JTWC. This dataset includes the position of cyclone center, the minimum surface pressure, and maximum surface wind speed every $6 \mathrm{~h}$, which are primarily estimated from cloud patterns and features. In the analysis of cyclone track, cases with maximum surface winds exceeding $17.2 \mathrm{~ms}^{-1}$ forming in the $\mathrm{BoB}$ area (defined as $5-25^{\circ} \mathrm{N}, 75_{-}$ $100^{\circ}$ E, see Fig. 1a) were used. For the examination of cyclone structure, data from satellite infrared and microwave sensors were used. In particular, the rainfall rate of microwave product was mainly used because this allows us to see the rain patterns within rainbands, which are normally masked by upper-level cloud shields and can not be seen from infrared imagery. The infrared cloud-top blackbody temperature $\left(T_{B B}\right)$ used here is the globally merged infrared (Global-IR) data with full resolution $(\sim 4 \mathrm{~km})$ every half hour, provided by the National Aeronautics and Space Administration (NASA) Earth-Sun System Division. The surface rain rate and precipitable water are provided by Remote Sensing Systems (RSS), where the daily orbital data of a microwave radiometer are mapped to a $0.25^{\circ} \times 0.25^{\circ}$ grid and stored in a single binary file. For the Nargis case, data corrected by five microwave instruments (SSM/I F13-15, TRMM/ TMI, and AMSR-E) were available. To examine the change in rain rate with time (Fig. 4), half-daily composite maps of rainfall were obtained by simply 

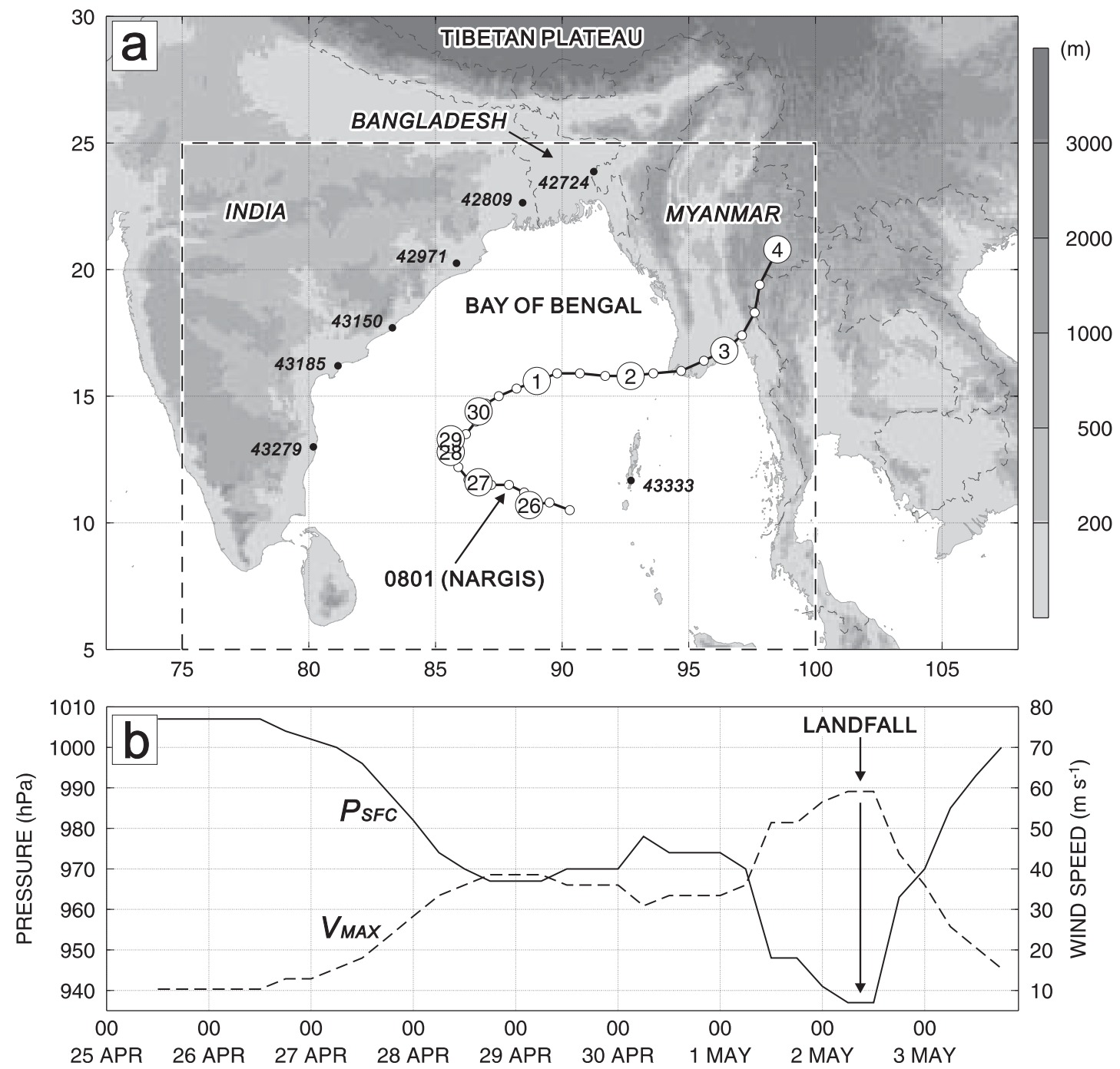

Fig. 1. (a) Track of Cyclone Nargis and topography of the surrounding areas. The track is plotted every $6 \mathrm{~h}$, and the location at 00 UTC of each day is indicated by a circle with a number. The broken rectangle shows the area of analysis of cyclone track. Location of upper-air soundings (with five-digit WMO station code), used in this study, is also plotted. (b) Series of the minimum pressure (solid line) and maximum wind speed (dashed line) at the sea surface.

averaging orbital data of the five sensors within each half day. This dataset allows us to examine the trend of cyclone's development for more than a day.

The environmental conditions of Nargis were examined using the six-hourly objective analysis dataset, derived from the Japan Meteorological Agency (JMA) Climate Data Assimilation System (JCDAS). This dataset makes use of the same data-assimilation system as the Japanese 25-year Reanalysis (JRA-25, Onogi et al. 2007) and is operated in almost real time. The dataset consisted of the geopotential height, temperature, humidity, and two horizontal wind components at the surface and at the standard pressure levels. The horizontal domain covers the whole globe $\left(90^{\circ} \mathrm{S}-90^{\circ} \mathrm{N}\right.$, $0-357.75^{\circ} \mathrm{E}$ ) with a horizontal grid spacing of $1.25^{\circ} \times 1.25^{\circ}$. Since the location of cyclone center on the reanalysis data is not always the same as the best-track position, analyses of wind fields (Section 5) were performed using the location of minimum height at $1,000 \mathrm{hPa}$ in the reanalysis data. To confirm the reproducibility of a large-scale flow in the reanalysis data, upper-air sounding data at 
operational stations along the coast of the BoB, obtained from the University of Wyoming, were subserviently used.

\section{Track and intensity of Cyclone Nargis}

The track of Nargis is shown in Fig. 1a. This cyclone was first identified as a tropical depression on 25 April. The cyclone track was northwestward in the first two days and almost stationary near $\left(13.0^{\circ} \mathrm{N}, 85.5^{\circ} \mathrm{E}\right)$ until 29 April. After that, it turned northeastward or eastward and reached the coastal area near Yangon, Myanmar, on 2 May. Time series of the minimum pressure and maximum wind speed at the surface (Fig. 1b) indicate that the cyclone intensification can be separated into two stages. The first one consists of the first three days until 29 April, in which the surface pressure dropped to $967 \mathrm{hPa}$ within the first two days (27 and 28 April) and recovered to some degree. The following stage is from 30 April through 2 May, including a period in which the cyclone re-intensified rapidly to $937 \mathrm{hPa}$ within $24 \mathrm{~h}$ before landfall. The cyclone track (Fig. 1a) shows that these two stages roughly correspond to the periods until stagnation and after that (i.e., eastward movement), respectively. The change in the cyclone structure and environmental features during the two stages are described in the following sections.

To highlight the peculiarity of the Nargis's track, Fig. 2 shows the track of all cyclones in the $\mathrm{BoB}$

\section{CYCLONE TRACK (1979-2008)}
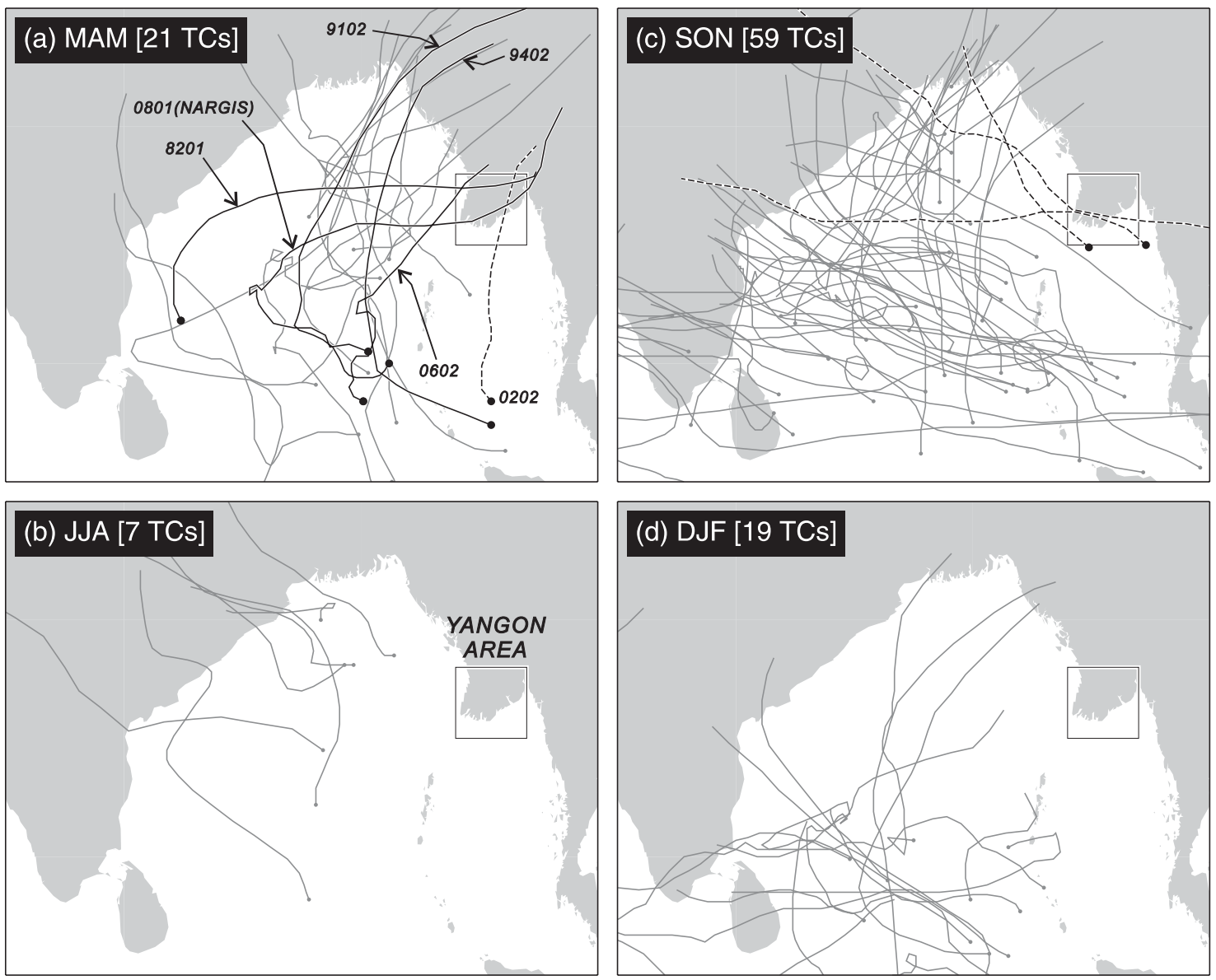

Fig. 2. Cyclone tracks in the Bay of Bengal in each season for recent 30 years. Solid circles indicate the start of track. Cyclones forming in April are drawn by solid black lines, and those passing over the Yangon area in other months are indicated by dashed black lines, while the others are shown in gray. The four-digit number of labeled cases indicates the combination of two-digit year and two-digit cyclone number in this year, as given by JTWC. 
area in each season between 1979 and 2008. In general, there are two typical cyclone tracks, one with a northward movement and the other with a northwestward one. The former is generally seen in spring (MAM), and the latter is common during summer (JJA), while the autumn (SON) and winter (DJF) seasons are characterized by a mixture of the two. The location of the landfall depends mainly on the direction of movement; the former usually reaches Bangladesh, while the latter tends to make landfall on the east coast of India. This figure also shows that the number of cyclones passing through the Yangon area (highlighted by a rectangle) is small and their occurrence is concentrated in two seasons (MAM and SON). Some of the cases focused here are labeled by the combination of twodigit year and two-digit cyclone number, such as "0801" for Nargis. There are only three cyclones (8201, 0602, and 0801 in Fig. 2a) that moved eastward or northeastward toward the Yangon area.

Table 1 lists the characteristics of cyclones in the Yangon area from a quantitative viewpoint. The total number of cyclones reaching the Yangon area is only seven for the 30 years of the record, and the fraction of the all the cyclones in the BoB is only $6.6 \%$, showing the peculiarity of the occurrence of Myanmar cyclones. The occurrence is concentrated in spring and autumn, and, in particular, the fraction peaks in April (60\%). The track of all cyclones in April, highlighted by solid black lines in Fig. 2a,

Table 1. Number of cyclones in the Bay of Bengal and Yangon area for each month in recent 30 years (19792008) and the fraction of cyclones entering the Yangon area.

\begin{tabular}{lccc}
\hline & \multicolumn{2}{c}{ Number of TCs } & $\begin{array}{c}\text { Fraction } \\
(\%)\end{array}$ \\
\cline { 2 - 3 } Month & Bengal & Yangon & 0.0 \\
\hline Jan. & 6 & 0 & 0.0 \\
Feb. & 0 & 0 & 0.0 \\
Mar. & 1 & 0 & 60.0 \\
Apr. & 5 & 3 & 6.7 \\
May & 15 & 1 & 0.0 \\
June & 6 & 0 & 0.0 \\
July & 1 & 0 & 0.0 \\
Aug. & 0 & 0 & 16.7 \\
Sep. & 6 & 1 & 4.0 \\
Oct. & 25 & 1 & 3.6 \\
Nov. & 28 & 1 & 0.0 \\
Dec. & 13 & 0 & 6.6 \\
\hline Total & 106 & 7 & \\
\hline
\end{tabular}

is characterized by the landfall in the northeastern coast of the $\mathrm{BoB}$, including the Yangon area. This suggests that cyclones may reach Myanmar if they form in April, although the total number is small.

Next, we take a close look at the intensity of spring cyclones reaching the Yangon area. Figure 3 shows the time series of the intensity of four cyclones (including Nargis) between April and May. This series clearly shows that three of them (8201, 0602, and 0801) that formed in April are similar to rapid intensification $\left(\geq 15.4 \mathrm{~ms}^{-1}\right.$ in $24 \mathrm{~h}$, defined by Kaplan and DeMaria 2003) within two days before landfall. As shown in Fig. 2a, these cyclones are also similar in their eastward or northeastward movement in the period from recurvature through landfall. In contrast, another case (0202) in May is characterized by the weak intensity $\left(<30 \mathrm{~ms}^{-1}\right)$ and northward movement without recurvature (see Fig. 2a). This suggests that spring cyclones moving eastward or northeastward tend to intensify rapidly just before hitting Myanmar. It should be also added that two other April cyclones (9102 and 9402 in Fig. 2a) also experienced rapid intensification before landfall (not shown).

So far, it is evident that the track of Nargis was quite rare among former cyclones over the BoB. On the other hand, it is noteworthy that the track record also shows that a limited number of former cyclones with a similar track developed in a concentrated period (i.e., April). Moreover, they are similar to Nargis in terms of rapid intensification immediately before landfall. This suggests common characteristics of their environmental conditions and provides motivation to investigate the background fields associated with the recurvature and intensification before landfall.

\section{Change in the cyclone structure}

The change in the Nargis's structure was analyzed using both satellite infrared and microwave products. Figure 4 shows the series of the cloudtop temperature and surface rainfall rate within a $250-\mathrm{km}$ radius from the cyclone center. These values are marked by a sudden dip of cloud-top height and rainfall rate on 29 April, which divides the stage of high cloud activity into two stages, before and after this. These two stages correspond to those separated in terms of surface pressure and wind speed (Fig. 1b). After adding one more stage during genesis, further analyses were performed by separating the whole period into three stages as below, 


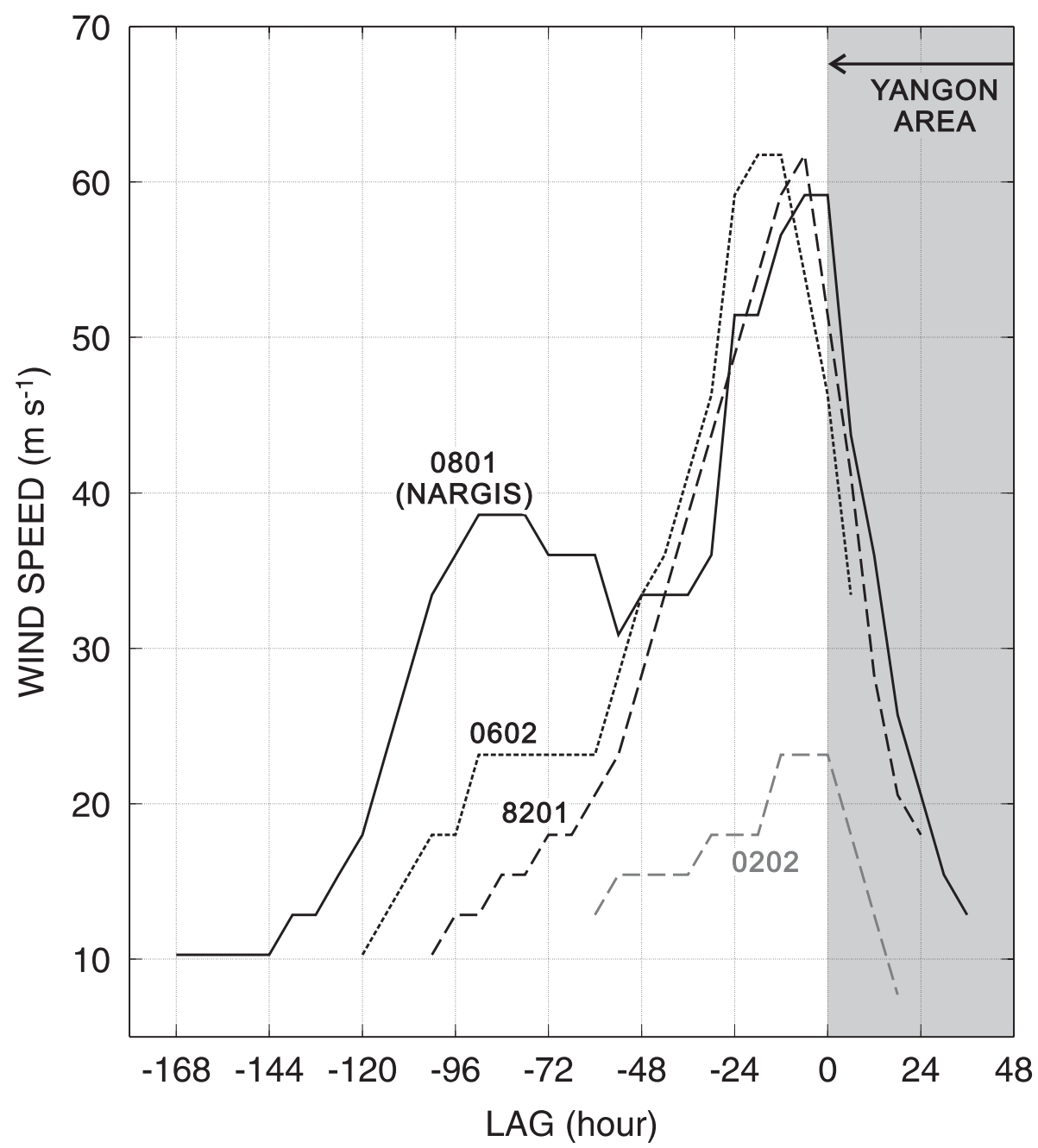

Fig. 3. Time series of the maximum surface wind speed associated with Nargis and other cyclones entering the Yangon area between April and May in 1979-2008. The horizontal axis is represented by the time lag with which a cyclone entered the Yangon area.

- Stage 0 (from 24 through 26 April),

- Stage 1 (from 27 through 29 April), and

- Stage 2 (from 30 April through 2 May).

They roughly correspond to the initial stage with northwestward movement, the first intensification with a following decline near $\left(13.0^{\circ} \mathrm{N}, 85.5^{\circ} \mathrm{E}\right)$, and the second intensification with eastward movement until landfall.

The structural change during Stage 1 is described using the series of the horizontal distributions of cloud-top, surface rainfall, and precipitable water (Fig. 5). This stage is marked by the development and breakdown of the axisymmetric rainfall pattern near the cyclone center, with significant changes in the precipitable-water distribution. An area of deep clouds (with $T_{B B}$ lower than $-70^{\circ} \mathrm{C}$ ) with intense rainfall $\left(\geq 8 \mathrm{~mm} \mathrm{~h}^{-1}\right)$ was concentrated on the center until 27 April (Fig. 5a). The precipitable water was higher than $60 \mathrm{~mm}$ in the vicinity of the cyclone. A rainfall pattern near the center had been axisymmetrized until the following day (Fig. 5b) on which the cyclone intensity reached the first peak (Fig. 1b). After that, outer spiral rainbands (labeled "A" and "B") with deep cloud tops $\left(T_{B B} \leq-70^{\circ} \mathrm{C}\right)$ formed in the western side and separated from the cyclone center (Figs. 5c and d). The outgoing speeds of rainbands $\mathrm{A}$ and $\mathrm{B}$ relative to the cyclone center were approximately 17 and $8 \mathrm{~ms}^{-1}$, respectively. This separation concurred with a significant 


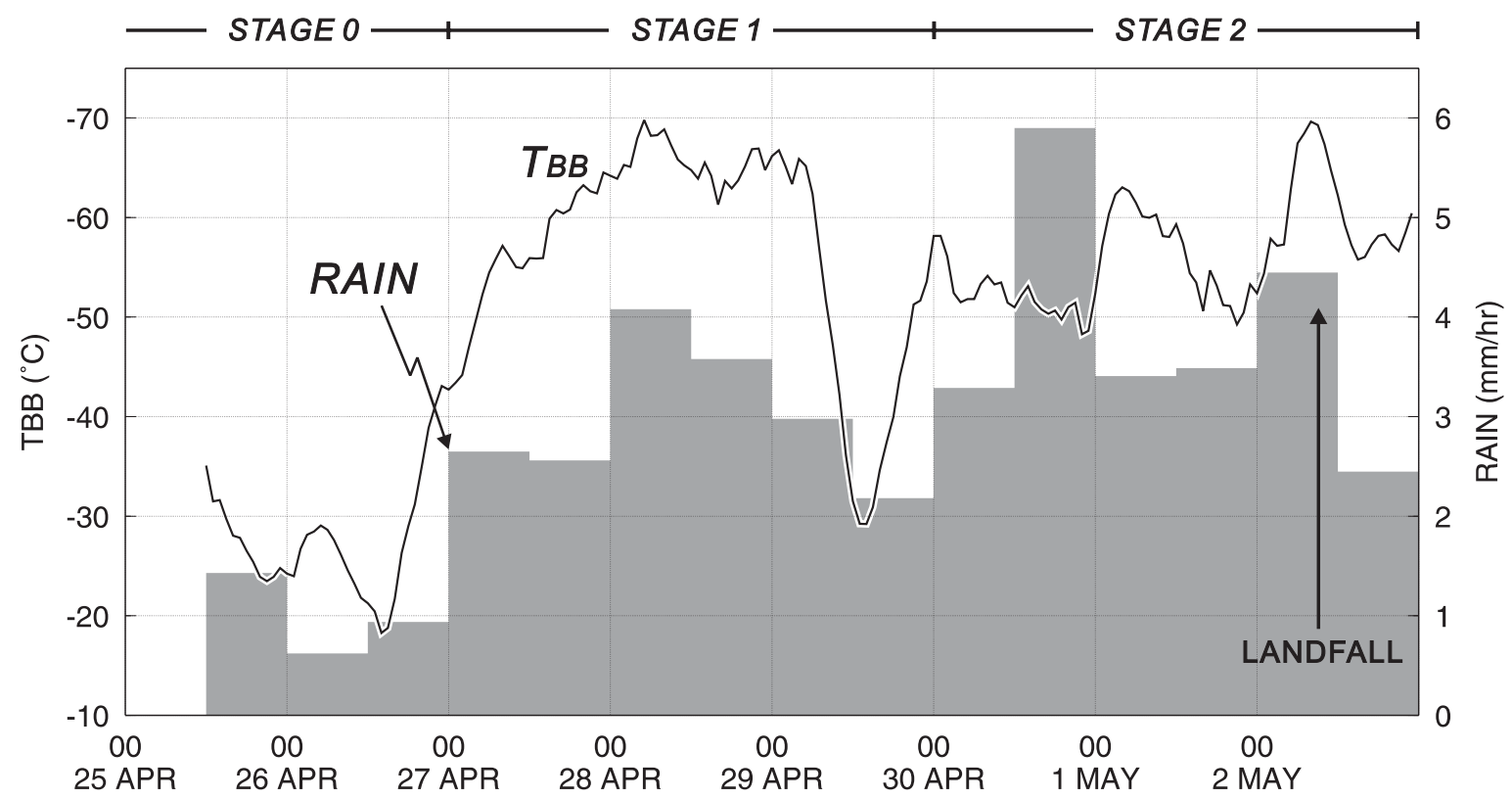

Fig. 4. Time series of the cloud-top temperature and microwave-derived rainfall rate, averaged within a 250$\mathrm{km}$ radius of the cyclone center.

decrease of precipitable water on the western side (highlighted by a white arrow), which suggests the intrusion of dry air. The rainband separation was followed by the sudden decreasing of cloud tops (i.e., increasing of $T_{B B}$ ) on 29 April (Fig. 5d). The rainfall distribution near the center became asymmetric at the same time.

On the other hand, the structural change during Stage 2 (Fig. 6) is characterized by the recovery of the axisymmetric rainfall distribution near the center. A round shape of deep cloud area was also recovered around the cyclone center (left panel of Fig. 6d). It is noteworthy that the rapid intensification on 1 May (Fig. 1b) corresponds to the recovery of the axisymmetric structure. In addition, another outer spiral rainband $(\mathrm{C})$, formed to the south of the center, did not move away from the center. The distributions of precipitable water indicate moistening in the southern side.

These results indicate that the weakening (intensification) of Nargis corresponds to the breakdown (recovery) of the axisymmetric inner structure. The intensity change according to the modification of the cyclone's internal dynamics was demonstrated by an idealized numerical simulation by Wang (2002). It is plausible that the behavior of outer spiral rainbands may have influenced the change in the inner structure. It is known that an outer spiral rainband usually has a vertical structure similar to a tropical squall line (Powell 1990) and the downdrafts of rainbands can block the flow into the cyclone center (Wang and Wu 2004). The separation of outer rainbands from the cyclone body may allow a surrounding airmass to flow into it. As for Nargis, if the low precipitable water to the west of the cyclone is assumed to have been dry air, this rainband separation would have caused dry-air intrusion, causing the convective activity near the cyclone center to decrease. The characteristics of the surrounding flow structure, associated with the intensity change, are described using reanalysis data in the next section.

\section{Environmental conditions}

The horizontal distributions of the reanalyzed winds and equivalent potential temperature $\left(\theta_{e}\right)$ at 925 and $600 \mathrm{hPa}$, averaged in each stage, are shown in Fig. 7. The environment during Stage 1 (Fig. 7b) is characterized by a northerly flow at $600 \mathrm{hPa}$ with $\theta_{e}$ lower than $330 \mathrm{~K}$ to the northwest of the recurving cyclone track (drawn by a red line). This northerly flow prevailed only in the middle troposphere $(700-400 \mathrm{hPa}$, figures omitted) and was very dry, with a relative humidity of less than $10 \%$ (not shown). This flow corresponds to the area of low precipitable water observed to the west 
(a)

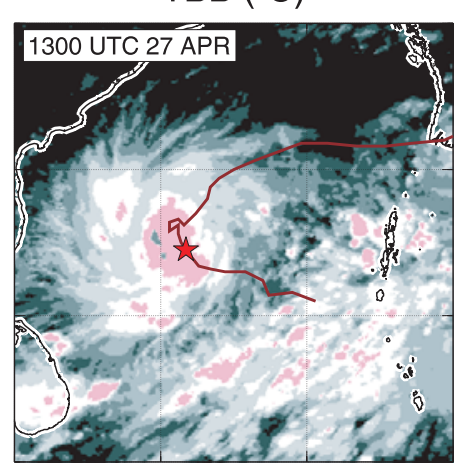

(b)

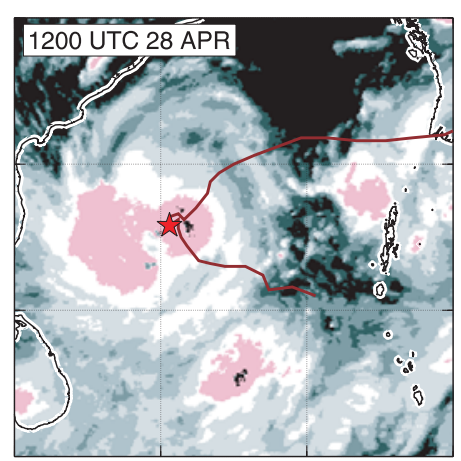

(c)

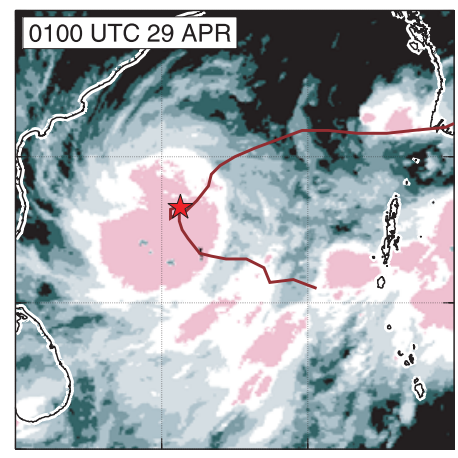

(d) 20

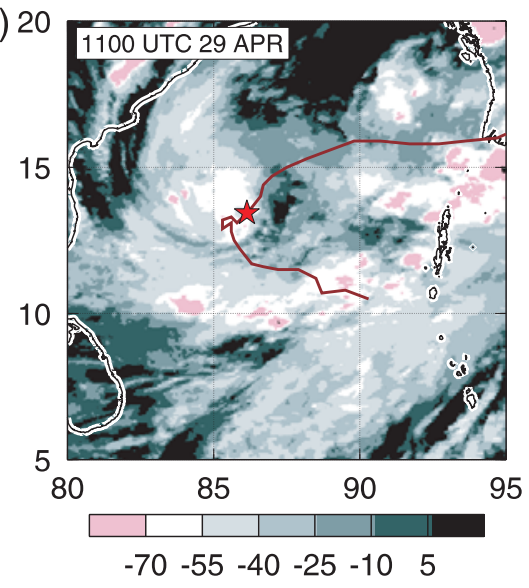

RAIN $\left(\mathrm{mm} \mathrm{h}^{-1}\right)$
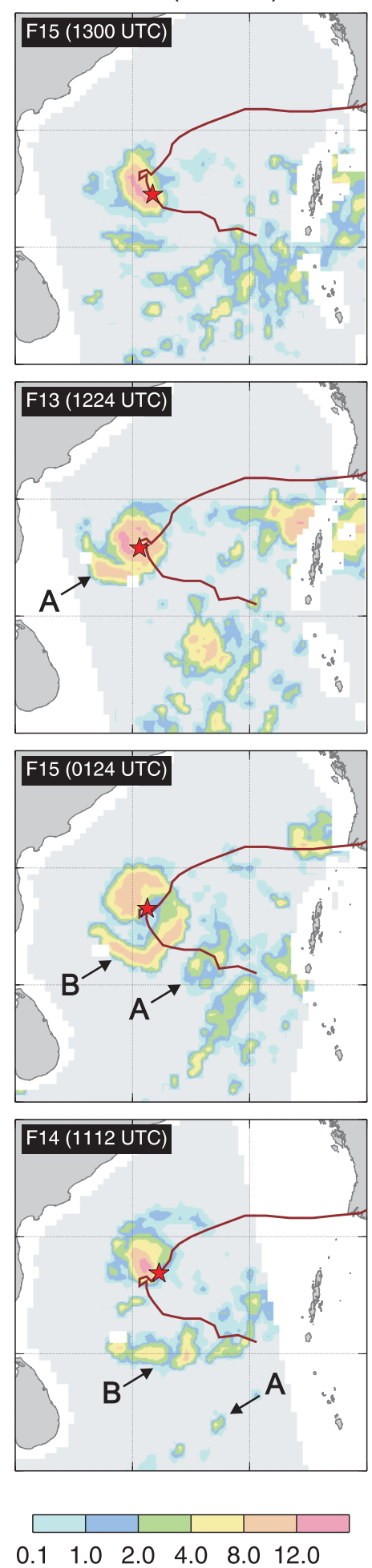

PW (mm)
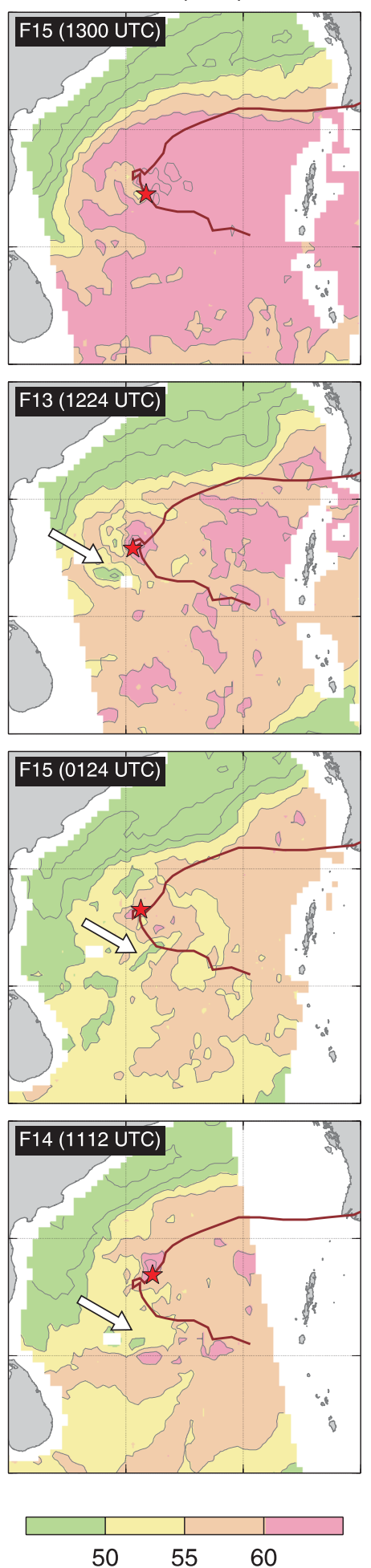

Fig. 5. Horizontal distributions of the cloud-top temperature, surface rainfall rate, and precipitable water during Stage 1 (27-29 April). 
(a)

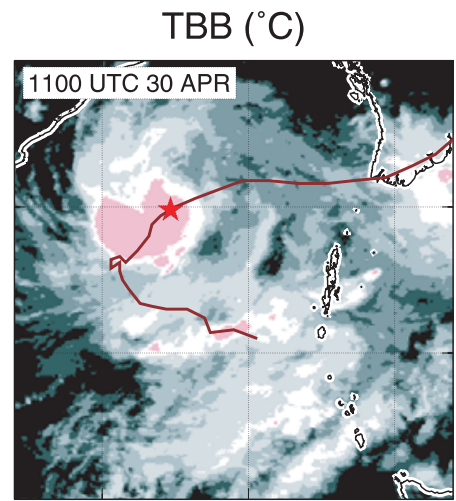

(b)

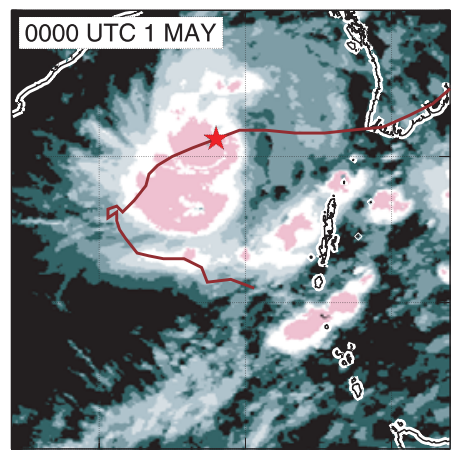

(c)

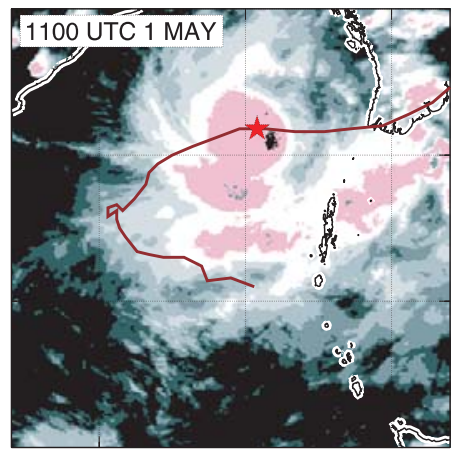

(d)

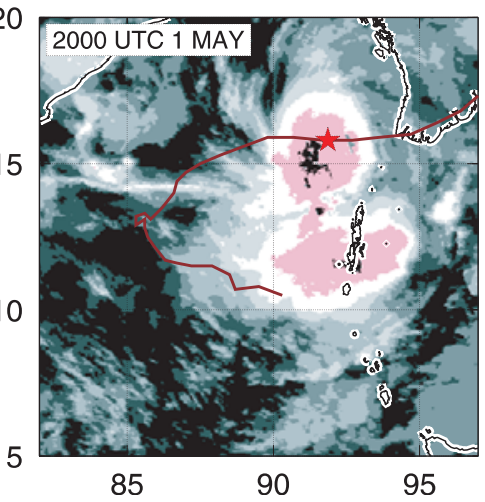

$\operatorname{RAIN}\left(\mathrm{mm} \mathrm{h}^{-1}\right)$
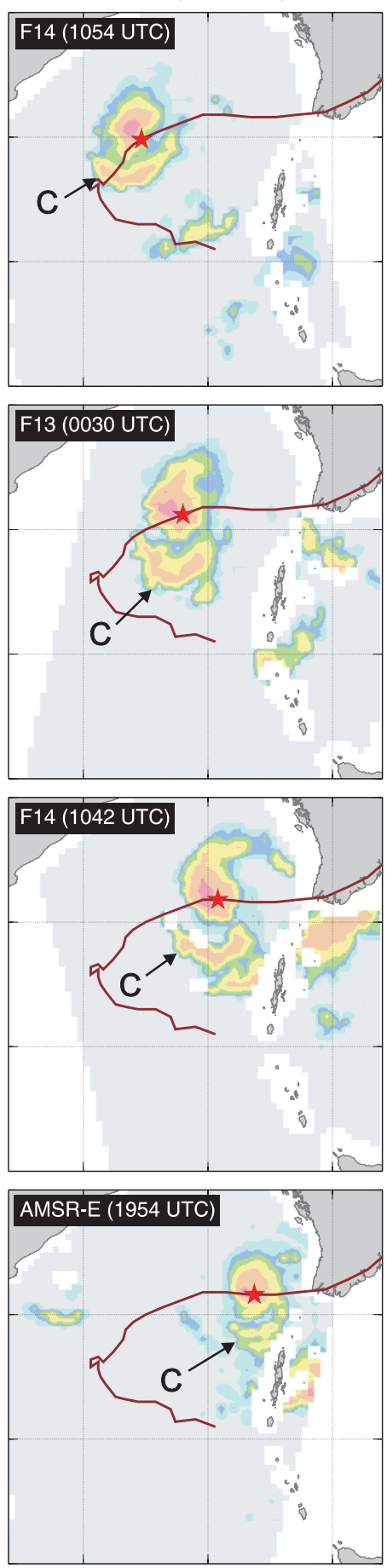

PW (mm)
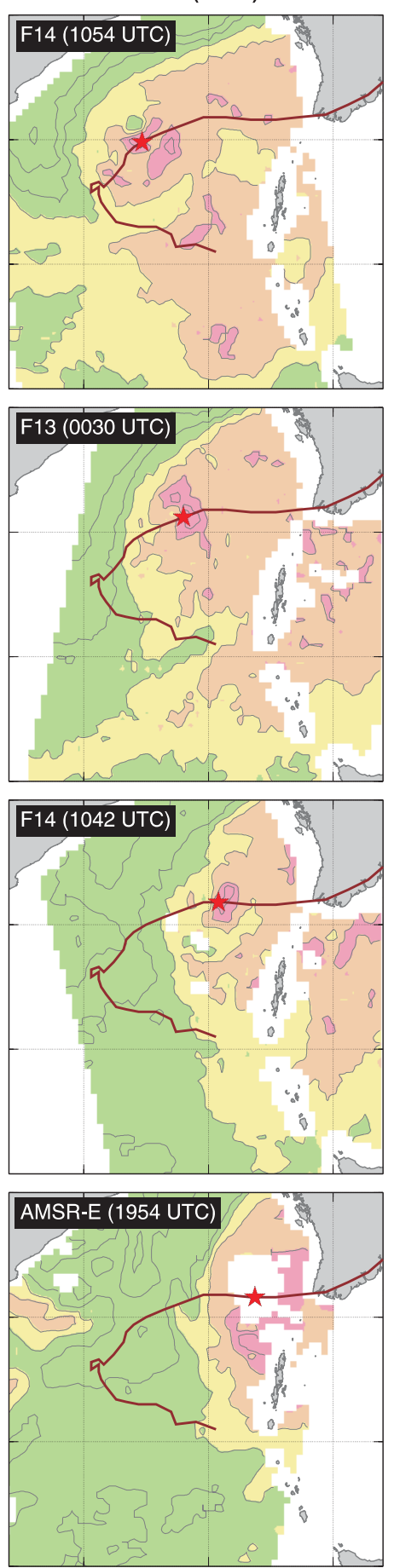

Fig. 6. Same as Fig. 5, but for Stage 2 (30 April-2 May). 

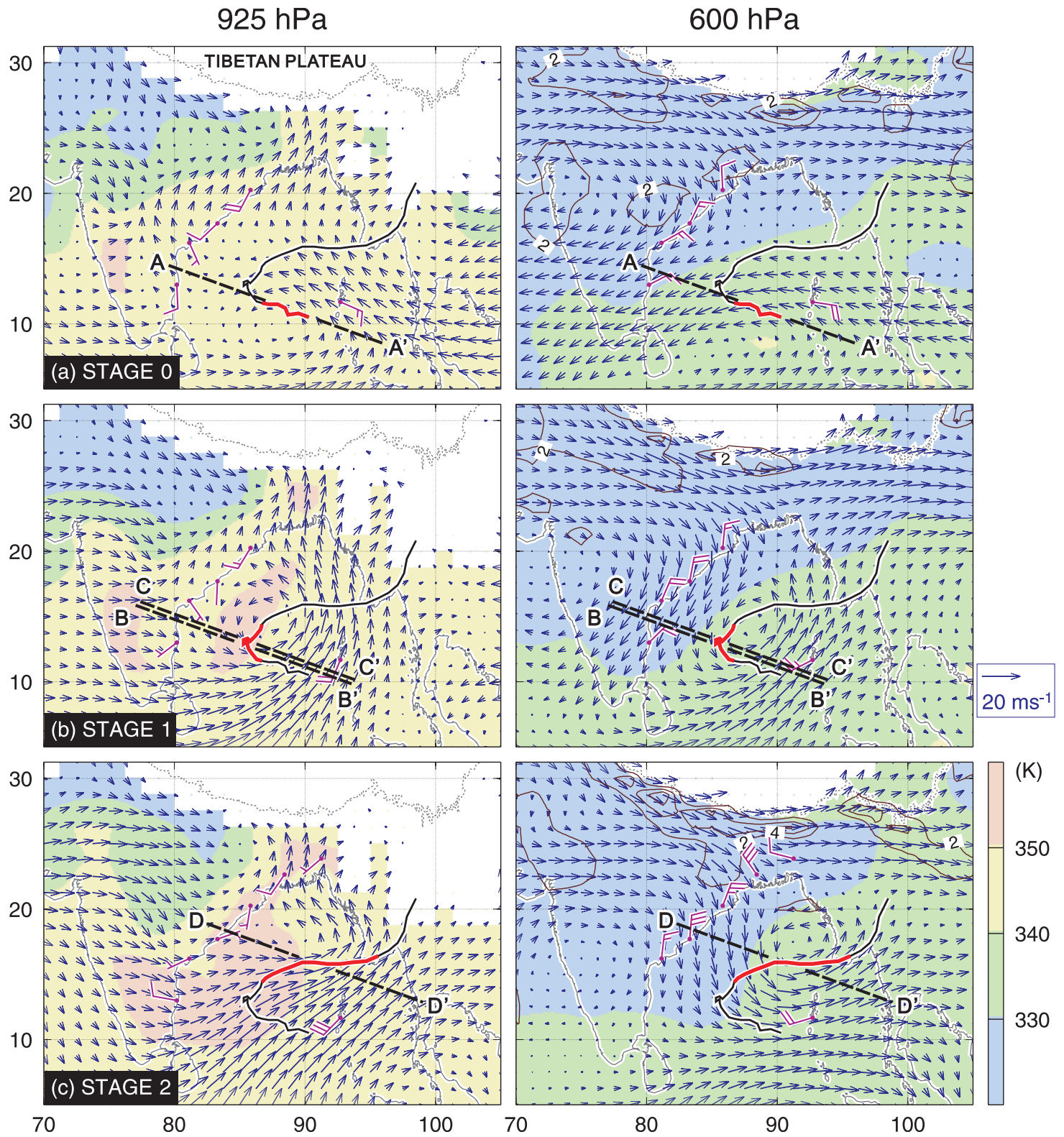

Fig. 7. Horizontal distributions of $\theta_{e}$ and wind vector at 925 and $600 \mathrm{hPa}$ averaged in (a) Stage 1 (24-26 April), (b) Stage 2 (27-29 April), and (c) Stage 3 (30 April-2 May). The segment marked with a bold red line indicates the cyclone track during each period. Coast lines and the contours of $3000-\mathrm{m}$ altitude are drawn with solid and dashed gray lines, respectively. In the panels corresponding to $600 \mathrm{hPa}$, the contours of downdrafts greater than $2 \mathrm{hPa} \mathrm{h}^{-1}$ are also superimposed. Observed winds are represented by a full wind barb of 10 knot and a half one of 5 knot.

of Nargis (described in the previous section). It is noteworthy that the dry flow branched off from a northwesterly subtropical jet near the southern rim of the Tibetan Plateau. This jet prevailed in the layer between 700 and $200 \mathrm{hPa}$ and was characterized by descending motion on the periphery of the plateau (as shown by contours). The subsidence, which results from the mechanical effect of the plateau and usually prevails until April (Sato and Kimura 2007), causes the dry conditions (with low relative humidity). Since the southward branch of dry air was not significant in Stage 0 (Fig. 7a), it 


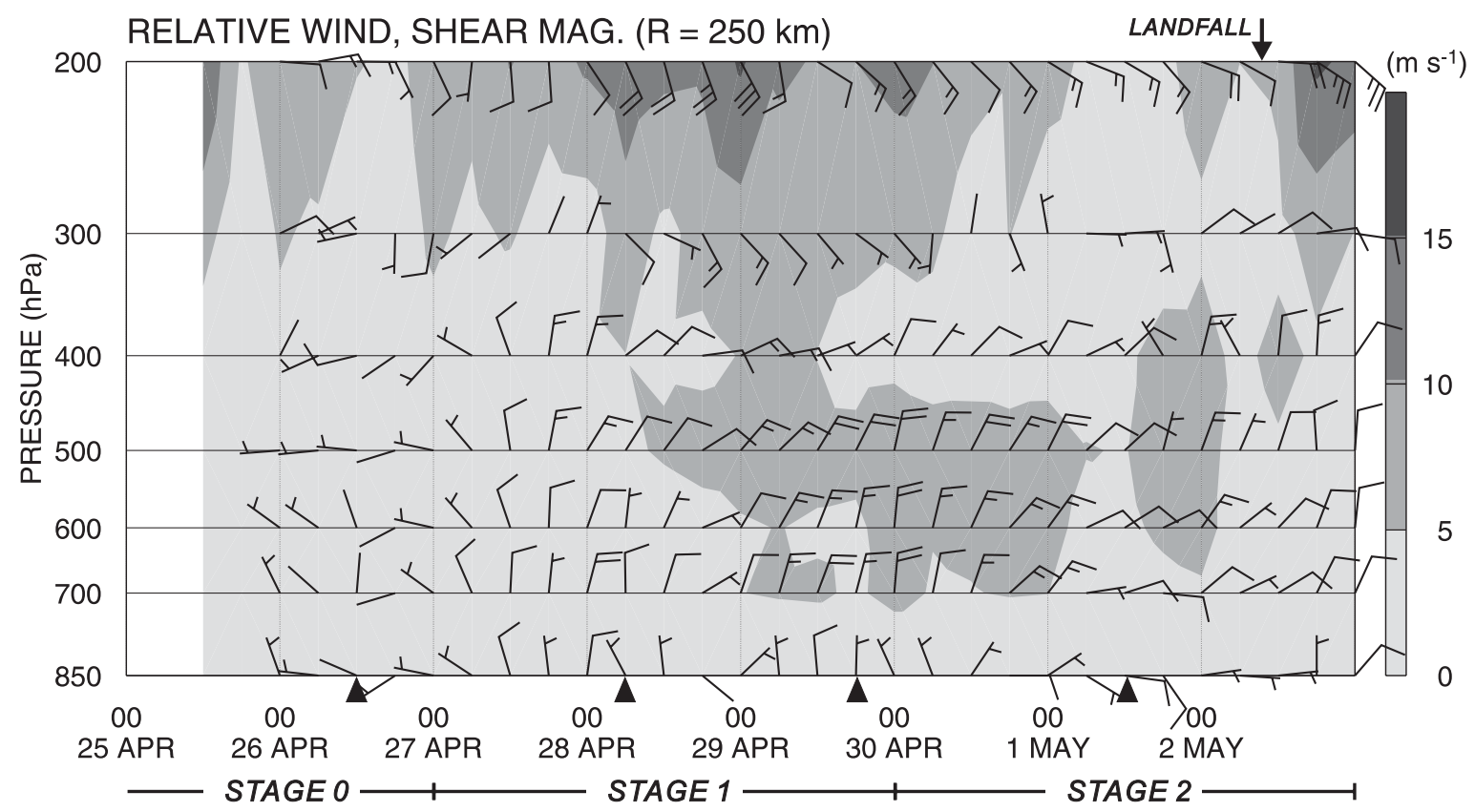

Fig. 8. Vertical time section of the horizontal wind barbs relative to the cyclone motion and the magnitude of vertical shear (gray scale) calculated between each pressure level and $850 \mathrm{hPa}$. Data within a $250-\mathrm{km}$ radius from the cyclone center were used. Solid triangles indicate the hour of vertical cross sections shown in Fig. 9.

is plausible that this branch intensified due to the lowering of geopotential height over the BoB due to cyclone development. In addition, it must be noted that the development of the large-scale cyclonic flow over the BoB in the reanalysis data did not result from the inclusion of an artificial vortex, which is referred to as "typhoon bogus" technique (Onogi et al. 2007). Wind barbs, observed at upper-air stations along the coast (superimposed in Fig. 7), also show the change in large-scale flow corresponding to the development of cyclonic flow between Stages 0 and 1.

In Stage 2 (Fig. 7c), although the mid-level northerly was still prevalent, a significant change was that this flow combined with a southwesterly and meandered to the south of the cyclone. The meander of the mid-level flow may have affected the cyclone motion and intensity. To examine the relevance of the surrounding flow to the intensification, mean horizontal winds within a $250-\mathrm{km}$ radius of the cyclone center (on the reanalysis data, see Section 2) were calculated at each pressure level. The zonal steering current, represented as the average of mean winds between 700 and $300 \mathrm{hPa}$, increased from $1.5 \mathrm{~ms}^{-1}$ (on 30 April) through
$5.5 \mathrm{~ms}^{-1}$ (on 1 May). The cyclone's zonal motion was accelerated from 2.1 through $7.3 \mathrm{~ms}^{-1}$ during this period. This acceleration concurred with rapid intensification and the recovery of the axisymmetric cyclone structure, as described above. Figure 8 shows a vertical time section of the storm-relative mean horizontal winds and the magnitude of vertical shear between each level and $850 \mathrm{hPa}$. The northerly relative winds, corresponding to the midlevel dry flow, were prevalent between 700 and $500 \mathrm{hPa}$ in 29-30 April. This flow caused a vertical shear exceeding $5 \mathrm{~ms}^{-1}$ between 850 and $500 \mathrm{hPa}$ on these days. It is noteworthy that the vertical shear weakened temporarily on 1 May, when the cyclone experienced rapid intensification. At 0600 UTC 1 May, the shear magnitude between 850 and $200 \mathrm{hPa}$ decreased to $5 \mathrm{~ms}^{-1}$, which is favorable for rapid intensification from the viewpoints of statistics and empiricism in the North Atlantic basin (Kaplan and DeMaria 2003; DeMaria 2009).

To describe, in more detail, the flow structure and thermodynamic conditions near the cyclone, snapshots of the vertical cross section across the cyclone center are shown in Fig. 9. The first intensification between Stages 0 and 1 (Figs. 9a and b) can 

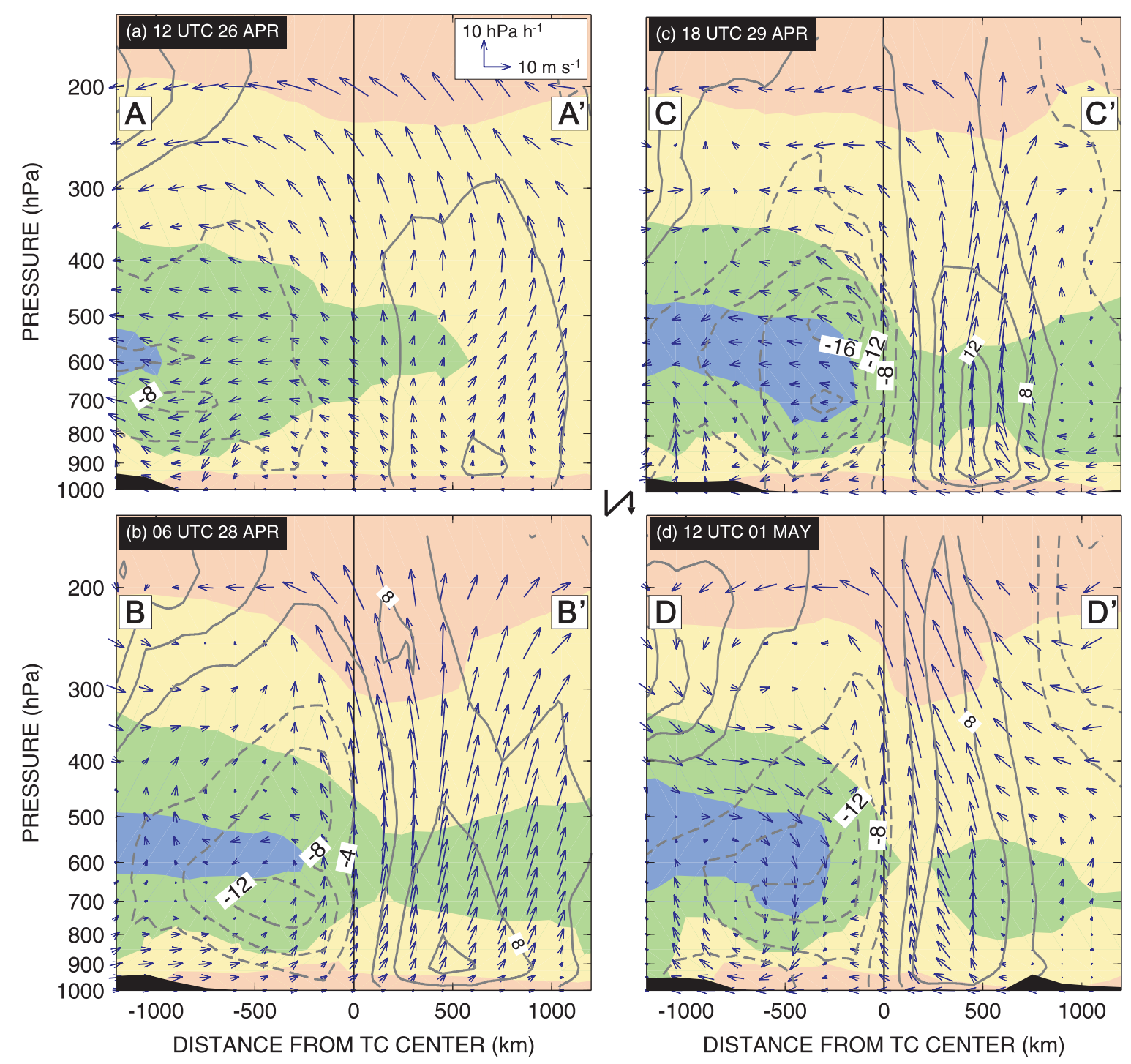

Fig. 9. Series of vertical cross sections across the cyclone center. The location of the sections is shown in Fig. 7. Each panel indicates the equivalent potential temperature (color with the same scale as in Fig. 7), wind vectors parallel to each section, and the horizontal wind component normal to the section (contour). The horizontal wind components are relative to the cyclone motion. The contour interval is $4 \mathrm{~ms}^{-1}$, and the zero contour is omitted. Negative (positive) contours indicate flows toward the front (rear) side. The topography is shown in black.

be identified from the increases in the upward motion and tangential wind components (drawn by contours) near the center. The downward extension of $\theta_{e}$ greater than $350 \mathrm{~K}$ near $200 \mathrm{hPa}$ is a manifestation of warm-core formation due to latent heating in the upper troposphere. At the same time, the low $-\theta_{e}$ air $(<330 \mathrm{~K})$ in the middle troposphere was approaching on the left (northwestern) side of the cyclone from behind the panel. During Stage 1
(Figs. 9b and c), this dry air penetrated further into the western part, and the updraft weakened near the center, causing the asymmetric structure. In Fig. 9c, the updraft tilted significantly rightward (i.e., southeastward) with height and the warm core in the upper troposphere shifted to the same direction. One interpretation is that the entrainment of dry air into a convective updraft reduced the positive buoyancy of rising air parcels, which 
caused the updraft to become shallow. This process is somewhat similar to that in a very early stage of extratropical transition (i.e., Step 1 of transformation stage, Klein et al. 2000), which is characterized by the initiation of an asymmetric distribution of clouds and precipitation due to environmental inflow of dry and cold air in the western quadrant.

The transition to Stage 2 (Fig. 9d) is marked by the recovery of the upstanding convective updraft and the upper-tropospheric warm core. It is evident that the recovery of the axisymmetric cyclone structure concurred with the relative retreat of the midtropospheric low $-\theta_{e}$ air due to the meander of this flow to the rear and south of the cyclone (Fig. 7c). As described above, this re-intensification is related to the increase of the steering flow and the temporal weakening of vertical shear. It should be noted that this process is different from the latter stage of extratropical transition (i.e., Step 2 of transformation, Klein et al. 2000), which occurs in a strong vertically sheared environment in a baroclinic zone. They argued that the interaction between a tropical cyclone and a preexisting, midlatitude baroclinic zone can produce ascending motion over tilted isentropic surfaces, which leads the modification of cyclone structure. In the present case, Fig. 7 shows that the meridional gradient of the equivalent potential temperature was weak within the $\mathrm{BoB}$ at $925 \mathrm{hPa}$, indicating a lack of lower-tropospheric baroclinic zone along the cyclone track. At this time, a weak baroclinic zone was located near the southern rim of the Tibetan Plateau (near $25^{\circ} \mathrm{N}$ ) where a subtropical jet was prevalent at $600 \mathrm{hPa}$. In addition, the recovery of the warm core over the center suggests the redevelopment of a tropical cyclone, rather than the transition to an extratropical one with a cold core.

Another important feature in the environment is the maintenance of warm and moist conditions in the lower troposphere. In the vertical sections (Fig. 9), an area of $\theta_{e}$ higher than $350 \mathrm{~K}$ exists near the surface throughout the analysis period despite the significant change in the midtropospheric flows. It is probable that the sustained conditionally unstable stratification in the vicinity of the cyclone supported the development of convective updraft, especially during the re-intensification stage. Since the high $\theta_{e}$ area existed mainly over the ocean, heat and moisture transports from the sea surface may have been a primary source of the warm and moist air. As mentioned in Section 1, the SST over the $\mathrm{BoB}$ was significantly higher than the climatologi- cal value. McPhaden et al. (2009a) recently reported that an ocean-moored buoy at $15^{\circ} \mathrm{N}, 90^{\circ} \mathrm{E}$ succeeded in capturing a high value of surface heat fluxes, with the sum of sensible and latent heat components reaching $600 \mathrm{Wm}^{-2}$. The simulation of surface heat fluxes over the BoB (Lin et al. 2009) also shows high value of the fluxes, with a large contribution of latent heat and a negative contribution of sensible heat.

In summary, the examination of the reanalysis data supported the evidence of dry-air intrusion and revealed the relevance of the midtropospheric flow to the cyclone intensity change. The analyses suggested the importance of a southward branch of mid-tropospheric dry flow from the subtropical jet near the Tibetan Plateau on the track and intensity of Nargis. This case study also suggests that the plateau has a significant influence on tropicalcyclone motion over the BoB in spring. These results prompt other questions related to the effect of a midtropospheric flow on the rapid intensification of former cyclones (8201 and 0602, described in Section 3) just before their hitting Myanmar. Thus, additional analyses of the environmental conditions of these cyclones were performed. The results are described in the next section.

\section{Environmental conditions of former severe cyclones hitting Myanmar in spring}

The participation of a midtropospheric flow on the cyclone intensification in the past two cases (8201 and 0602) is examined using horizontal and vertical sections at $24 \mathrm{~h}$ before landfall (Fig. 10). Both of these cyclones and Nargis are similar in their rapid intensification after recurvature and before landfall (as described in Section 3). In both cases, the horizontal distribution at $600 \mathrm{hPa}$ shows the significant meandering of a flow to the south of the cyclone center. A northerly flow with $\theta_{e}$ lower than $330 \mathrm{~K}$ also exists behind the cyclone, as in the case of Nargis. Further, in both cases, this northerly flow originated from the southern periphery of the Tibetan Plateau, where subsidence was prevalent, although the main jet just south of the plateau was weak in the case of 0602 . The vertical sections (bottom panels) show the prevalence of updrafts with the formation of an upper-tropospheric warm core near the cyclone center. In each case, midtropospheric low- $\theta_{e}$ air $(<330 \mathrm{~K})$ existed at this time about $300 \mathrm{~km}$ left (northwest) of the center, which is almost the same distance as that in the case of Nargis (Fig. 9d). The environmental vertical shear 


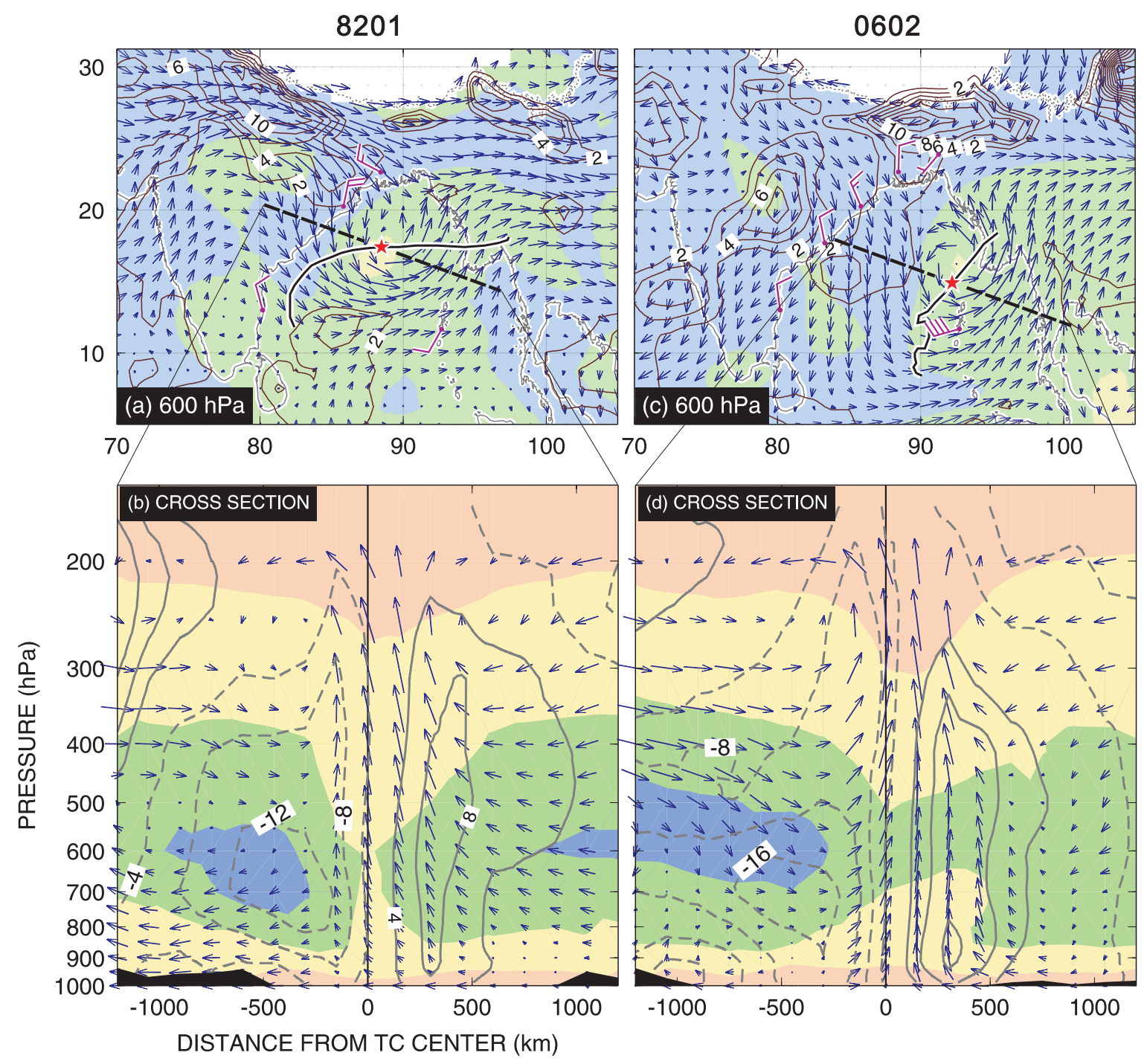

Fig. 10. Horizontal distribution at $600 \mathrm{hPa}$ and vertical section of winds and equivalent potential temperature in the cases of 8201 and 0602 that hit Myanmar. The winds are ground-relative in the horizontal distribution and storm-relative in the vertical section. The time displayed is $24 \mathrm{~h}$ before landfall, i.e., 12 UTC 3 May 1982 (a and b) and 06 UTC 28 April 2006 (c and d). Observed wind barbs are superimposed. The color scale, vector scale, and contour interval are the same as those in Figs. 7 and 9.

between 850 and $200 \mathrm{hPa}$ decreased temporarily to $5 \mathrm{~ms}^{-1}$ (in the 8202 case) and $6 \mathrm{~ms}^{-1}$ (in the 0602 case) during rapid intensification. These characteristics of the two past cyclones are similar to those of Nargis and suggest a common process of rapid intensification; the meandering of a midtropospheric flow causes the recurvature and acceleration of cyclone motion, while a temporal decrease of vertical shear allows a cyclone to intensify rapidly. These findings, therefore, suggest that a branch of a subtropical jet flowing to the south of the Tibetan
Plateau can act as a determining factor on the cyclone track and intensity change over the BoB. However, we must emphasize that this role is limited in spring because the subtropical jet is usually predominant in this area from winter until spring (Sato and Kimura 2007).

\section{Summary and discussion}

In this paper, we report some significant characteristics of Cyclone Nargis (2008): its unusual track, changes in its structure, and the environmental con- 
ditions associated with the cyclone's rapid intensification just before landfall. The track of Nargis is characterized by an eastward movement toward Myanmar after a recurvature over the Bay of Bengal $(\mathrm{BoB})$, which is quite rare in the cyclone track record of 30 years (1979-2008). On the other hand, the track record also shows that two other cyclones (i.e., 8201 and 0602) had a similar track in the same season. Moreover, they are similar to Nargis in terms of their rapid intensification within $48 \mathrm{~h}$ of landfall.

The structure of Nargis was examined using infrared and microwave satellite products, which showed a significant structural change before and after the recurvature. The cyclone intensity was first increased and then temporally weakened due to the breakdown of the axisymmetric inner structure into an asymmetric one. The separation of the outer spiral rainband and decrease of precipitable water to the west of the cyclone concurred during this stage. After recurvature, the cyclone intensified rapidly, and the structure was marked by the recovery of the axisymmetric rainfall distribution near the center, with an increase in precipitable water. Thus, in further analysis, we focused on the environmental characteristics relating to the cyclone's recurvature and structural change.

The reanalysis data show that the decrease in the precipitable water in the western part corresponded to the intrusion of dry air in the middle troposphere. This dry flow branched off from a subtropical jet in the north of the bay, which was characterized by its dryness due to the subsidence motion in the southern periphery of the Tibetan Plateau. This northerly flow forced the cyclone's movement from northward to eastward, while the intrusion of dry air into the cyclone center interrupted the convective development. After recurvature, a change in the steering flow accelerated the cyclone motion, and this caused the temporal decrease of environmental vertical shear, leading to the redevelopment of convection and rapid intensification of the cyclone. The branch of the midtropospheric dry flow to the south of the cyclone center was also analyzed in the environment of two former severe cyclones hitting Myanmar, suggesting the applicability of a similar scenario to their intensification.

These results suggest the importance of a midtropospheric flow as a determinant of the cyclone track and intensification over the $\mathrm{BoB}$ in spring. They also suggest that the Tibetan Plateau influences the jet to stay on the south side. Therefore, we can attribute the unusual track and rapid intensification of Cyclone Nargis to the unique topography and seasonal flow structure. These factors may also influence the general characteristics of cyclones in this basin, which recurve to the south of $20^{\circ} \mathrm{N}$ (Murty and Neralla 1992), while recurvature usually occurs to the north of $20^{\circ} \mathrm{N}$ in the Western North Pacific (e.g., Riehl 1972) and the North Atlantic Ocean (Evans and McKinley 1998). For cyclone forecasting, it is necessary to monitor the behavior and strength of subtropical jets, especially in the middle troposphere, as important factors for spring cyclones, as well as the sea-surface temperature and tropical wave activity.

Although this study has described the relevance of large-scale flow to the track and intensity of Nargis, the detailed mechanisms of the rapid intensification was beyond the scope of this paper. Since numerical simulations of Nargis (Kuroda et al. 2009; Saito et al. 2009; Yoshida et al. 2009) successfully reproduced the rapid intensification of Nargis to some degree, it is expected that the role of mesoscale processes on the intensification can be clarified using the outputs of the simulations. For better understanding of track change and intensification over the $\mathrm{BoB}$, it is also important to enhance satellite and in situ observing systems. The development of a new ocean buoy array in the Indian Ocean (McPhaden et al. 2009b), in conjunction with an earth-observing satellite network, will enable further understanding of the role of environmental conditions on the structure, track, and intensification of tropical cyclones.

\section{Acknowledgments}

The authors express their gratitude to Ms. M. Fujita of JAMSTEC for collecting the observational and reanalysis data immediately after the Nargis case. Thanks are also extended to an editor and anonymous reviewers for their constructive criticisms and helpful comments. The Global-IR data were acquired as part of the NASA's EarthSun System Division and archived and distributed by the Goddard Earth Sciences (GES) Data and Information Services Center (DISC) Distributed Active Archive Center (DAAC). The microwave datasets (SSM/I, TMI, AMSR-E, and QuikScat) were produced by Remote Sensing Systems and sponsored by the NASA Earth Science REASoN DISCOVER Project, the AMSR-E Science Team, and the NASA Ocean Vector Winds Science Team. Data are available at "www.remss.com." 
The upper-air sounding data were obtained from the Department of Atmospheric Science, University of Wyoming (weather.uwyo.edu).

\section{References}

Alam, M. M., M. A. Hossain, and S. Shafee, 2003: Frequency of Bay of Bengal cyclonic storms and depressions crossing different coastal zones. Int. J. Climatol., 23, 1119-1125.

DeMaria, M., 2009: A simplified dynamical system for tropical cyclone intensity prediction. Mon. Wea. Rev., 137, 68-82.

Evans, J. L., and K. McKinley, 1998: Relative timing of tropical storm lifetime maximum intensity and track recurvature. Meteor. Atmos. Phys., 65, 241245.

Frank, W. M., and P. E. Roundy, 2006: The role of tropical waves in tropical cyclogenesis. Mon. Wea. Rev., 134, 2397-2417.

Gray, W. M., 1968: Global view of the origin of tropical disturbances and storms. Mon. Wea. Rev., 96, 669-700.

Hsu, H. H., C. T. Terng, and C. T. Chen, 1999: Evolution of large-scale circulation and heating during the first transition of Asian summer monsoon. $J$. Climate, 12, 793-810.

Jain, I., P. Chittibabu, N. Agnihotri, S. K. Dube, P. C. Sinha, and A. D. Rao, 2006: Simulation of storm surges along Myanmar coast using a location specific numerical model. Natural Hazards, 39, 7182.

Kaplan, J., and M. DeMaria, 2003: Large-scale characteristics of rapidly intensifying tropical cyclones in the North Atlantic basin. Wea. Forecasting, 18, 1093-1108.

Kikuchi, K., and B. Wang, 2009: Formation of Nargis (2008) and tropical cyclones in the Northern Indian Ocean associated with tropical intraseasonal oscillation. J. Meteor. Soc. Japan, 88, 475-496.

Kikuchi, K., B. Wang, and H. Fudeyasu, 2009: Genesis of tropical cyclone Nargis revealed by multiple satellite observations. Geophys. Res. Lett., 36, L06811, doi:10.1029/2009GL037296.

Klein, P. M., P. A. Harr, and R. L. Elsberry, 2000: Extratropical transition of Western North Pacific tropical cyclones: An overview and conceptual model of the transformation stage. Wea. Forecasting, 15, 373-395.

Kuroda, T., K. Saito, M. Kunii, and N. Kohno, 2009: Numerical simulations of Myanmar cyclone Nargis and the associated storm surge. Part I: Forecast experiment with NHM and simulation of storm surge. J. Meteor. Soc. Japan, 88, 521-545.

Lin, I. I., C. H. Chen, I. F. Pun, W. T. Liu, and C. C. Wu, 2009: Warm ocean anomaly, air sea fluxes, and the rapid intensification of tropical cyclone
Nargis (2008). Geophys. Res. Lett., 36, L03817, doi:10.1029/2008GL035815.

McPhaden, M. J., G. R. Foltz, T. Lee, V. S. N. Murty, M. Ravichandran, G. A. Vecchi, J. Vialard, J. D. Wiggert, and L. Yu, 2009a: Ocean-atmosphere interactions during cyclone Nargis. EOS Trans. $A G U$, 90, 54-55.

McPhaden, M. J., G. Meyers, K. Ando, Y. Masumoto, V. S. N. Murty, M. Ravichandran, F. Syamsudin, J. Vialard, L. Yu, and W. Yu, 2009b: RAMA: The research moored array for African-AsianAustralian monsoon analysis and prediction. Bull. Amer. Meteor. Soc., 90, 459-480.

Mohanty, U. C., M. Mandal, and S. Raman, 2004: Simulation of Orissa Super Cyclone (1999) using PSU/ NCAR mesoscale model. Natural Hazards, 31, 373-390.

Murty, T. S., and V. R. Neralla, 1992: On the recurvature of tropical cyclones and the storm surge problem in Bangladesh. Natural Hazards, 6, 275-279.

Onogi, K., J. Tsutsui, H. Koide, M. Sakamoto, S. Kobayashi, H. Hatsushika, T. Matsumoto, N. Yamazaki, H. Kamahori, K. Takahashi, S. Kadokura, K. Wada, K. Kato, R. Oyama, T. Ose, N. Mannoji, and R. Taira, 2007: The JRA-25 reanalysis. J. Meteor. Soc. Japan, 85, 369-432.

Pattanayak, S., and U. C. Mohanty, 2008: A comparative study on performance of MM5 and WRF models in simulation of tropical cyclones over Indian seas. Current Science, 95, 923-936.

Powell, M. D., 1990: Boundary layer structure and dynamics in outer hurricane rainbands. Part I: Mesoscale rainfall and kinematic structure. Mon. Wea. Rev., 118, 891-917.

Rao, D. V. B., and K. Ashok, 1999: Simulation of tropical cyclone circulation over Bay of Bengal using the Arakawa-Schubert cumulus parametrization. Part I-Description of the model, initial data and results of the control experiment. Pure Appl. Geophys., 156, 525-542.

Riehl, H., 1972: Intensity of recurved typhoons. J. Appl. Meteor., 11, 613-615.

Saito, K., T. Kuroda, M. Kunii, and N. Kohno, 2009: Numerical simulation of Myanmar cyclone Nargis and the associated storm surge. Part II: Ensemble prediction. J. Meteor. Soc. Japan, 88, 547-570.

Sato, T., and F. Kimura, 2007: How does the Tibetan Plateau affect the transition of Indian monsoon rainfall? Mon. Wea. Rev., 135, 2006-2015.

Sengupta, D., P. K. Ray, and G. S. Bhat, 2002: Spring warming of the Eastern Arabian Sea and Bay of Bengal from buoy data. Geophys. Res. Lett., 29, 1734, doi:10.1029/2002GL015340.

Singh, O. P., T. M. Ali Khan, and M. S. Rahman, 2000: Changes in the frequency of tropical cyclones over the North Indian Ocean. Meteor. Atmos. Phys., 75, $11-20$. 
Subbaramayya, I., and S. R. M. Rao, 1984: Frequency of Bay of Bengal cyclones in the post-monsoon season. Mon. Wea. Rev., 112, 1640-1642.

Vaidya, S. S., P. Mukhopadhyay, D. K. Trivedi, J. Sanjay, and S. S. Singh, 2004: Prediction of tropical systems over Indian region using mesoscale model. Meteor. Atmos. Phys., 86, 63-72.

Wang, Y., 2002: Vortex Rossby waves in a numerically simulated tropical cyclone. Part II: The role in tropical cyclone structure and intensity changes. $J$. Atmos. Sci., 59, 1239-1262.
Wang, Y., and C.-C. Wu, 2004: Current understanding of tropical cyclone structure and intensity changes - a review. Meteor. Atmos. Phys., 87, 257-278.

Webster, P. J., 2008: Myanmar's deadly daffodil. Nature Geoscience, 1, 488-490.

Yoshida, R., Y. Oku, T. Takemi, and H. Ishikawa, 2009: Satellite and modeling analyses of elliptical eye of devastating cyclone Nargis (2008). J. Meteor. Soc. Japan, (submitted). 